\title{
Innovative Methods of Reconstruction After Pelvic Tumor Resection
}

\author{
Kevin I. Perry $•$ Matthew P. Abdel • \\ David G. Lewallen · Peter S. Rose • \\ Franklin H. Sim
}

Published online: 21 December 2013

(C) Springer Science + Business Media New York 2013

\begin{abstract}
The goals of pelvic tumor treatment are first, to obtain clear margins and prevent tumor recurrence, and second, to preserve limb function whenever possible. Treatment of tumors around the pelvis remains a difficult problem. Challenges include both tumor resection and pelvic reconstruction. We have made significant advances in both treatment and reconstructive efforts over the last decade with advances in imaging techniques and prosthetic design. Nevertheless, reconstruction after pelvic tumor resection must be individualized for each patient. One must consider age, functional status, and the extent of the tumor before deciding on the best reconstruction option. The aim of this paper is to outline the available reconstructive techniques and to discuss our current preferred strategy for reconstruction of the pelvis after tumor resection.
\end{abstract}

This article is part of the Topical Collection on Ortho-oncology.

\author{
K. I. Perry $(\bowtie) \cdot$ M. P. Abdel · D. G. Lewallen · \\ P. S. Rose - F. H. Sim \\ Department of Orthopedic Surgery, Mayo Clinic, 200 First Street \\ S.W., Rochester, MN 55905, USA \\ e-mail: perry.kevin@mayo.edu \\ M. P. Abdel \\ e-mail: abdel.matthew@mayo.edu \\ D. G. Lewallen \\ e-mail: lewallen.david@mayo.edu \\ P. S. Rose \\ e-mail: rose.peter@mayo.edu \\ F. H. Sim \\ e-mail: sim.frankling@mayo.edu
}

Keywords Pelvic tumor resection - Periacetabular resection - Acetabular reconstruction - Tantalum metal . Pelvic limb salvage $\cdot$ Arthroplasty

\section{Introduction}

Pelvic limb tumors pose significant challenges for both patients and surgeons. Patients require an accurate diagnosis, treatment (and resection) plan, and execution, and when possible, reconstruction. Often the margin is narrow in critical areas (viscera and vessels), making local recurrence a major concern [1]. Prior to the advent of chemotherapy, patients often succumbed to their disease with very low 5-year survival rates. With modern imaging and treatment protocols, the prognosis for patients presenting with non-metastatic disease has improved and justifies aggressive surgical resections of pelvic malignancies. It has been well-established that properly selected patients who undergo limb-salvage procedures have better ambulatory and overall functional capacity than those who undergo external hemipelvectomy [2].

When deciding between an internal (i.e., limb salvage) and external hemipelvectomy, the surgeon must consider three critical structures: the lumbosacral plexus, the femoral neurovascular bundle, and the hip joint. It is generally accepted that in order to salvage the limb, the surgical team must be able to preserve two of these three structures. As such, a team approach is critical for success. It is important to involve spine, vascular, hip reconstructive, plastic, colorectal, and tumor surgeons for each case as needed. The goals of surgery should be to obtain clear margins and preserve limb function whenever possible.

The Enneking-Dunn classification for internal hemipelvectomies is based on the region of the innominate bone 
that is resected [3]. Type I resections involve the ilium, Type II resections include the periacetabular region, and Type III resections involve the ischiopubic region. Resections can be partial, complete, or extended. Extended Type I resections include en bloc resection of the sacral ala and are often referred to as Type IV resections. Compound resections involve concurrent resection of visceral structures. When visceral structures (such as bowel and bladder) are resected, we assume these wounds are inherently contaminated and that these patients are not candidates for immediate reconstruction.

When there is loss of bony continuity between the femur and the ipsilateral sacrum, the pelvic resection is considered unstable. Reconstruction should be considered in this setting as it has been demonstrated that function of the extremity is best when pelvic continuity is restored $[4,5 \bullet$. Conversely, if continuity between the femur and ipsilateral sacrum are maintained (as in partial Type I and complete Type III resections), generally no reconstruction is necessary.

\section{Pelvic Limb Salvage}

\section{Type I: Iliosacral Resections}

Iliosacral resections typically leave a defect from the sacroiliac (SI) joint to the level of the ilium just above the acetabulum. With regard to the necessity of reconstruction, the critical factor is the continuity of the SI joint. If any of the SI joint remains in continuity after resection, most surgeons agree that no pelvic reconstruction is usually necessary. Excellent functional results can be expected in this setting [6]. On the other hand, if there has been disruption of the SI joint, treatment options for these patients remains controversial. Our experience with leaving these patients flail has been that they have pelvic instability, major gait abnormalities, limb shortening, and continued pain. Nevertheless, others have had success with leaving these patients flail $[6,7]$. If reconstruction is chosen, pelvic stability can be re-established with the use of strut grafting or iliosacral fusion based on the distance between the remaining ilium and sacrum (Figs. 1, 2).

\section{Type III: Ischiopubic Resections}

Even complete Type III resections maintain continuity between the femur and ipsilateral sacrum. Therefore, no reconstruction is typically necessary and excellent functional outcomes are possible.

\section{Type II: Periacetabular Resections}

Periacetabular pelvic resections provide the surgeon with numerous reconstructive options that can be tailored based

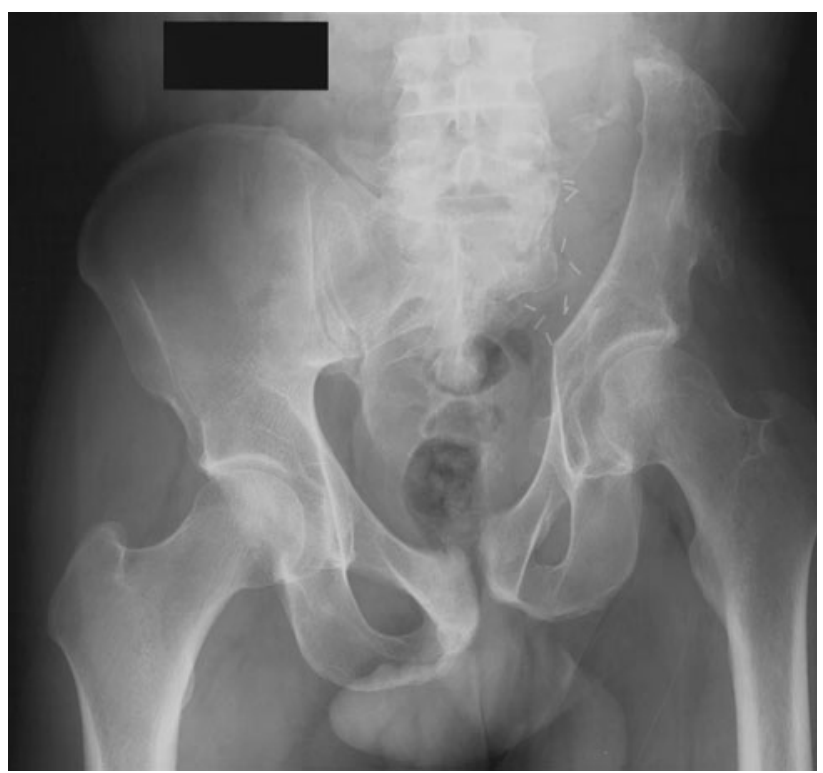

Fig. 1 A 36-year-old patient who had an iliosacral resection for chondrosarcoma. The pelvis was not reconstructed and after 4 years, this patient had continued pain, an unstable pelvis, and a severe limp

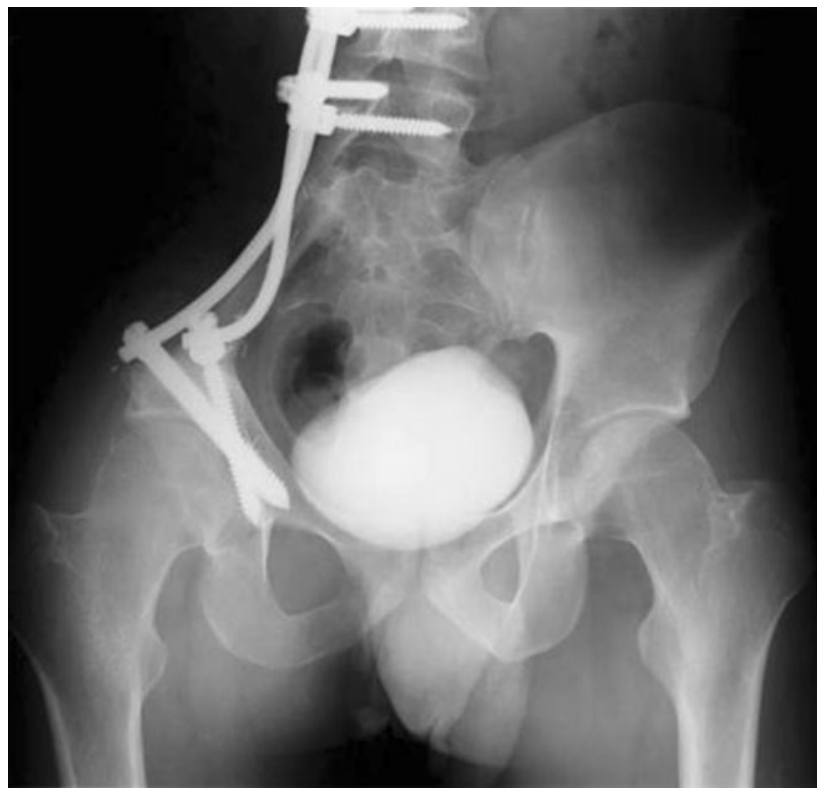

Fig. 2 Example of an iliosacral resection that was carried out on a 21-year-old male for an Ewing's sarcoma. The pelvis was reconstructed with a vascularized free fibula. This patient went on to heal without complication, has no pain, and walks without a significant limp

on individual patient attributes and functional requirements. The defects left after these resections can be some of the most challenging reconstructions, as often attempts are made not only at re-establishing continuity of the femur and sacrum, but also in creating a new articulation to preserve hip motion. Of the reconstruction options that have been described, each has its own set of advantages and limitations. 


\section{Arthrodesis/Pseudoarthrodesis}

\section{Iliofemoral and Ischiofemoral Arthrodesis}

Fusion of the proximal femur to the remaining ilium can provide extremely durable results with a very reasonable functional outcome. Historically, this has been the reconstructive option of choice in young, active patients because of its durability (Fig. 3). Difficulties with union have been reported and, though the reported results with pseudoarthroses are not quite as good as patients with solid arthrodeses, the results are still quite favorable [8]. Still, the technique does have its limitations. Specifically, iliofemoral arthrodesis often causes limb shortening and can contribute to an impaired gait. Intercalary allografts can be added to address the problem of shortening, but this introduces another junction that can fail to unite, causing pseudoarthrosis. Ischiofemoral arthrodesis addresses the problem of limb shortening, but may contribute to a painful symphysis and has been shown to have a higher rate of non-union. Both ischiofemoral and iliofemoral arthrodesis provide good outcomes and can be used depending on the level of pelvic resection $[8,9]$.

\section{Iliofemoral Pseudoarthrosis}

Occasionally, a patient is best served by leaving the pelvic resection flail (i.e., a pseudoarthrosis), without attempt at reconstruction or arthrodesis. Pseudoarthroses are quite durable and can often provide a painless articulation with reasonable function. The benefits of the pseudoarthrosis are that it is technically less demanding and has a lower complication rate than iliofemoral or ischiofemoral

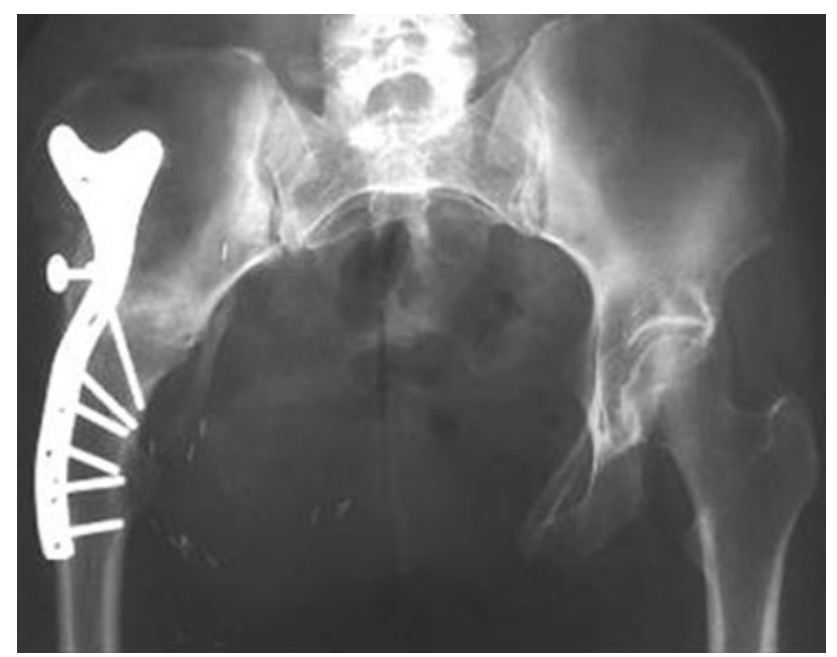

Fig. 3 An example of an iliofemoral arthrodesis. This patient was followed for 20 years with a good result, despite significant shortening and an impaired gait arthrodesis. This can be critical in the oncologic care of patients who may need a rapid, predictable resumption of chemotherapy post-operatively. Nevertheless, pseudoarthroses are typically not as functional as a solid arthrodesis. We tend to reserve these procedures mostly for more sedentary patients that are functionally less demanding.

Arthroplasty

Reconstruction of the pelvis with the use of endoprostheses has historically included the use of a saddle prosthesis, a custom prosthesis, or a massive pelvic allograft used in combination with total hip arthroplasty (THA). In recent years, however, we have expanded the arthroplasty reconstructive options with the use of highly-porous metal (i.e., tantalum). Acute reconstruction of the pelvis with tantalum components has become our treatment of choice in many patients.

\section{Saddle Prosthesis}

The saddle prosthesis (Fig. 4) has long been used in the setting of periacetabular resections $[10,11]$. It is technically less demanding, expedient, and provides reasonable stability while preserving leg length. Its limitations include its non-anatomic, high hip center, high rates of component migration (Fig. 5), fracture of the remaining ilium (Fig. 6), instability, and infection [12]. Cottias and colleagues [13]

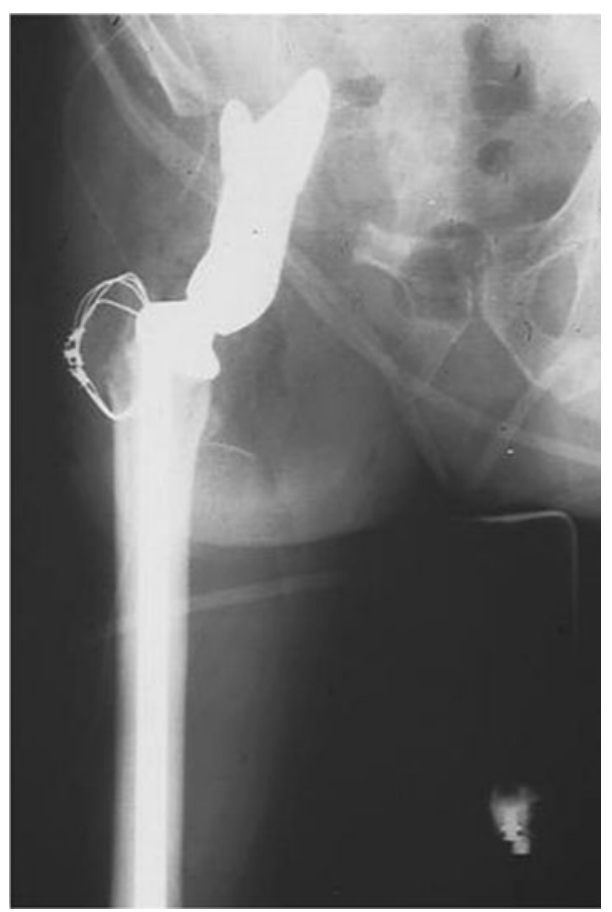

Fig. 4 The saddle prosthesis is expedient, provides good stability, and maintains length despite a high complication rate 


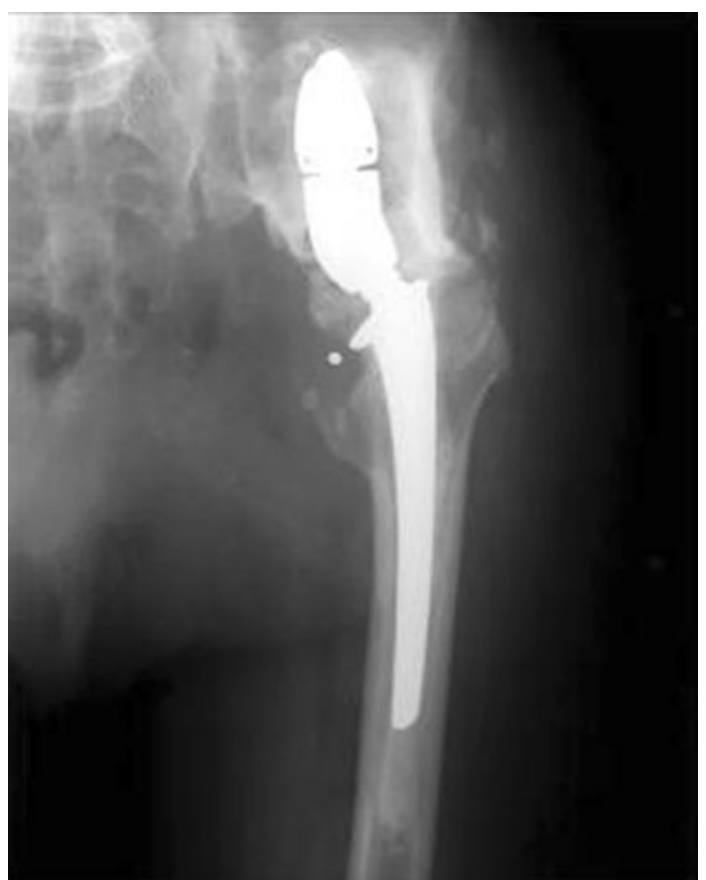

Fig. 5 An example of a saddle prosthesis that migrated after only 1 year

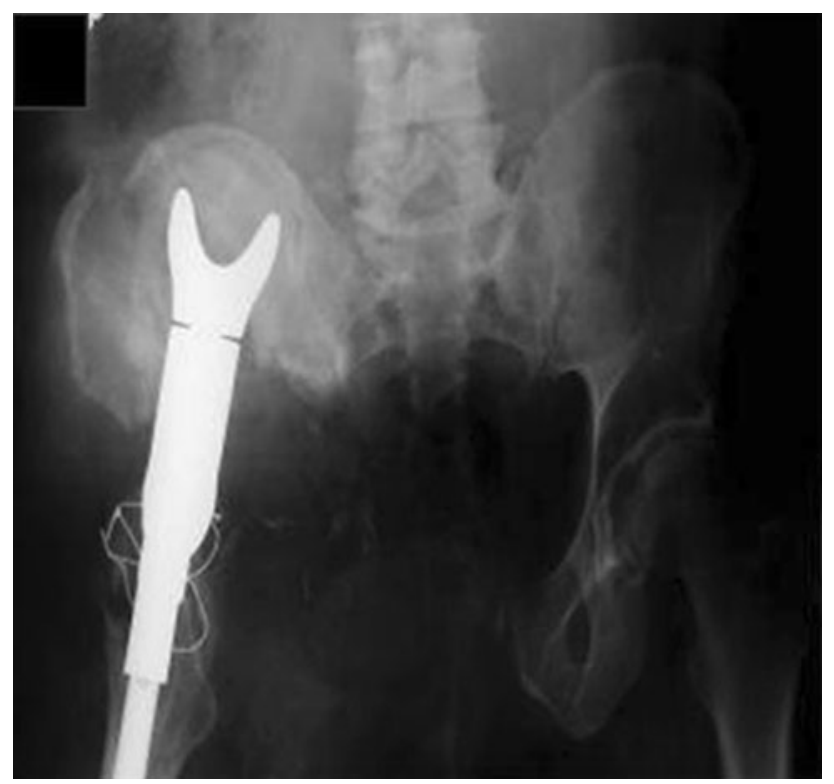

Fig. 6 Fracture of the remaining ilium 4 years after resection and saddle prosthesis reconstruction

reported their results with the use of the saddle prosthesis and found extraordinarily high complication rates with modest functional results.

\section{Massive Pelvic Allograft, THA, and Custom Prostheses}

Massive pelvic allografts have also been used in combination with THA with modest success $[14,15]$. With this concept, an allograft pelvis is obtained and ultimately contoured to fit the defect left by the periacetabular resection. After appropriate contouring, the allograft is fixed to the remaining pelvis and an acetabular component is inserted into the allograft bone. This has the benefit of providing better functional results and preserving limb length. Nevertheless, there is no potential for ingrowth of the acetabular component into the allograft bone, thus limiting durability. Moreover, the clinical results of massive pelvic allografts in this setting have been met with only modest results along with very high rates of wound complications, infections, and need for revision. The high rate of complications using this technique has tempered our optimism and limited its use in our practice.

Another reconstructive option comes in the form of the pedestal cup. With this implant, the long, modular pedestal allows the surgeon to place the articulating portion of the acetabular implant in a more anatomical position in the setting of massive pelvic bone loss. The use of the pedestal cup has been used with some success relative to traditional saddle prostheses [16]. This technique has been used in the case of massive acetabular defects in the revision THA setting and appropriately applied to periacetabular tumor resections. The major drawbacks of this technique include risk of dislocation and aseptic loosening associated with its use.

With the precision of MRI and CT imaging, some have advocated the use of custom tumor prostheses that can be constructed pre-operatively and implanted at the time of tumor resection [17]. The benefits of this technique include the ability to design and tailor an implant based on the exact level of resection and the anticipated bone stock that will remain. Still, these implants can be difficult to modify at the time of surgery and despite best attempts at preoperatively planning, the execution of the resection does not always perfectly follow the preoperative plan. Thus, the defect the surgeon is left with at the time of surgery may be different than what was anticipated for the custom prosthesis. The advent of computer navigation has provided the surgeon with an intraoperative tool to combat imprecision and allow for more accurate resection and reconstruction. This technology allows the surgeon to navigate areas in the pelvis where the tumor may be in close proximity to important anatomic structures. Navigation also plays a role in the reconstruction of the pelvis in that limb length and component positioning can be accurately assessed when normal anatomic landmarks may be missing due to tumor resection.

\section{THA and Tantalum Reconstruction}

A recent development in the field of pelvic tumor reconstruction has been with immediate reconstruction of the hip using highly-porous metals following oncologic resection of periacetabular tumors [18••]. The advent of highly-porous 


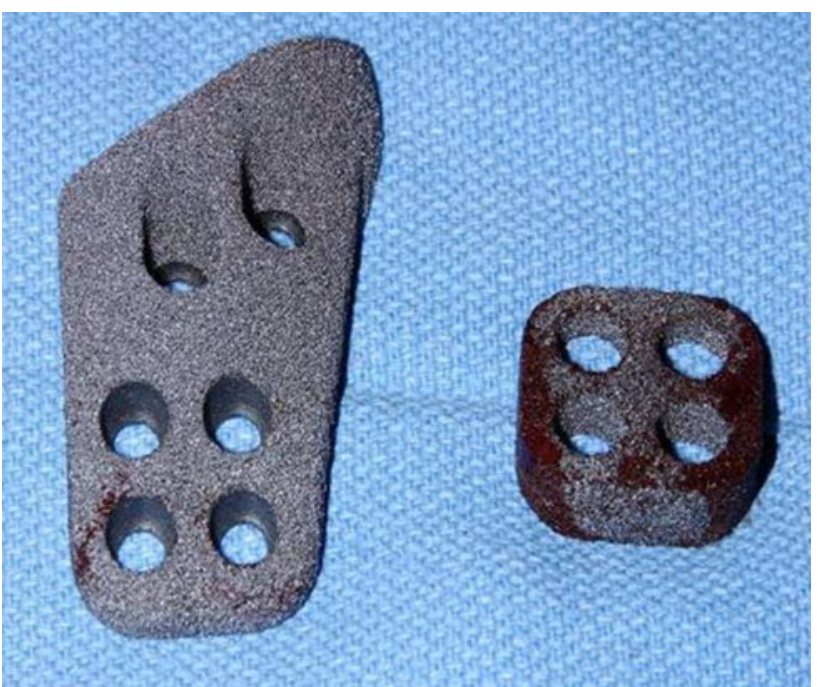

Fig. 7 An example of the available tantalum augments

metal (tantalum) acetabular components and augments (Fig. 7) has provided surgeons with an opportunity to achieve ingrowth of components into relatively small areas of native host bone. Tantalum provides a three-dimensional structure that is very similar to bone and has $70-85 \%$ porosity [19], providing a high-friction interface and excellent ingrowth capabilities.

Success with highly-porous tantalum components has been well-established in previously irradiated bone [20] and in non-oncologic reconstructions with massive acetabular/pelvic bone loss [19, 21-23]. We have expanded and adapted its use to highly functioning patients with periacetabular tumors. This technique has become our treatment of choice in select patients where adequate tumor margins can be achieved while still preserving enough ilium to allow initial stability of the implants and promote bony ingrowth of a tantalum acetabular component (with the addition of tantalum acetabular augments as needed). Our early experience with these acute reconstructions has shown excellent functional potential and similar rates of infection and dislocation to alternative procedures. We feel the ingrowth capability of tantalum has the potential to allow for a more durable prosthesis (than its alternatives) that is less likely to loosen over the course of a patient's lifetime. Nevertheless, further study and longer follow-up is necessary to validate this potential benefit of tantalum reconstruction after tumor resection.

After tumor resection, the reconstruction strategies associated with tantalum reconstruction are not dissimilar to any major reconstruction in the revision arthroplasty setting with major periacetabular bone loss. The surgeon must carefully assess the defect after the resection, achieve mechanical support of the construct with native host bone, maximize the surface contact area of the cup (and augments) with host bone, and restore normal anatomic relationships if possible. Although the boundaries for what constitutes an acceptable amount of host bone to allow ingrowth of the components have not yet been defined in the oncologic setting, we have found that a stable reconstruction is possible with minimal native bone.

\section{Technique}

Careful preoperative templating must be carried out to map out the predicted areas of resection and plan the appropriate reconstruction. Even with meticulous preoperative preparation, the reconstructive hip surgeon must be prepared for variations in the remaining bone stock at the time of surgery. Once the resection has been performed, a cavity should be prepared with reamers to accept an acetabular component. We prefer the use of a jumbo acetabular component to fill the defect. Typically, the surgeon has more bone in the anteroposterior (AP) plane than in the medial to lateral plane. After the acetabular cavity has been prepared, the surgeon should assess the defects surrounding the cavity, as there are often areas of deficiency that require the use of tantalum augments for support of the cup. This is best done by inserting a trial acetabular component and trialing different augments around the trial acetabular component. There are infinite iterations of the augments that can be used, but it is important to conceptualize the possibilities before insertion of the real acetabular component. Once the surgeon has a general sense of the defects involved and the possible augments that will be needed, the real acetabular component can be inserted. We use multiple screws (as many as the host bone will allow) through the acetabular component and augments to provide initial stability and maximize potential for bony ingrowth [24] (Figs 8, 9, 10). Often, it is necessary to use a helicoidal burr to make additional holes in the acetabular component to allow additional screws to be placed. Once the real acetabular component has been secured to the host bone, the augments that will best assist in providing initial stability of the acetabular component are placed using a small amount of bone cement between the augments and acetabular component to provide some additional fixation. The augments are then secured to host bone using screw fixation.

Often, the femur can be prepared in traditional fashion and the femoral component can be implanted into the femur based upon surgeon preference. Nevertheless, the surgeon must be aware of the fact that often a significant limb length discrepancy exists due to the new, higher hip center. Reconstruction of the femur with modular fluted tapered stems or tumor prostheses provide excellent options to address any discrepancy in leg length that may not be achieved with traditional prostheses. After insertion of the femoral component, a trial reduction should be carried out to ensure adequate stability of the hip. 


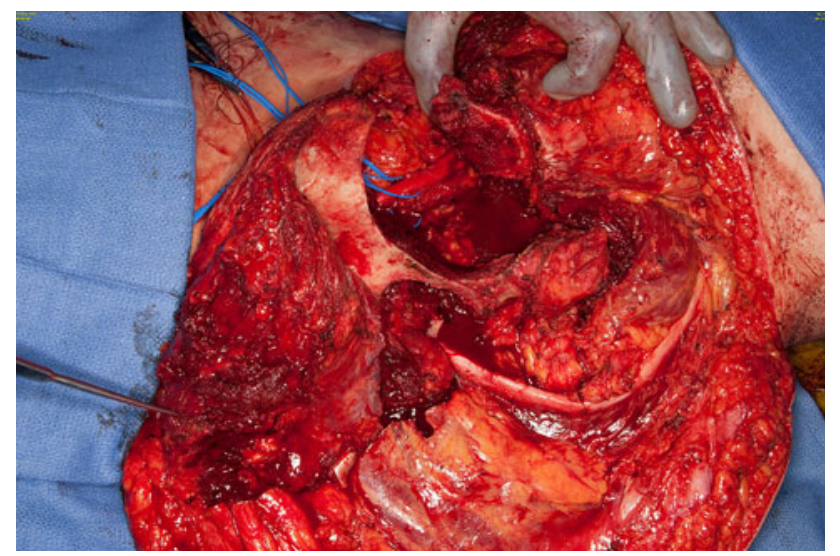

Fig. 8 The remaining hemipelvis prior to acute tantalum reconstruction after resection of chondrosarcoma in a 55-year-old female

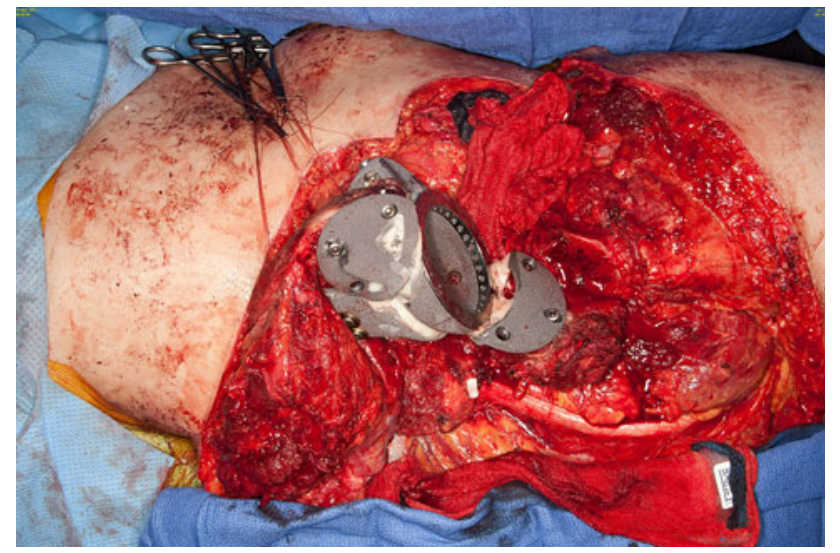

Fig. 9 The hemipelvis after tantalum reconstruction

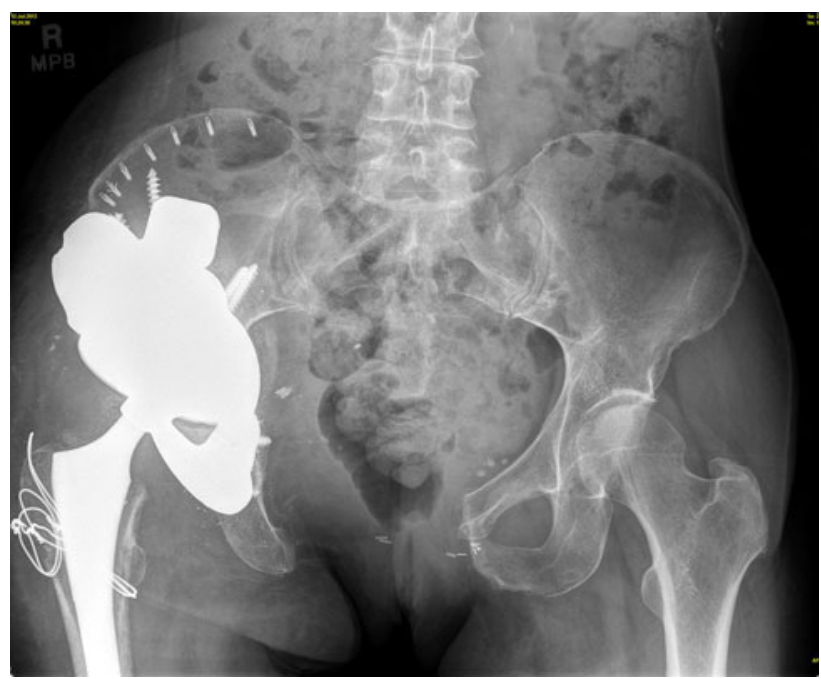

Fig. 10 AP pelvis X-ray after acute tantalum reconstruction of the pelvis

The advent of the dual-articulation acetabular cup system (or dual-mobility) has provided surgeons with another intraoperative option to maximize stability in this difficult patient population. Specifically, the dual-mobility construct allows for an increased head-neck ratio, theoretically reducing the risk of hip instability [25]. It has been our general practice to use the dual-articulation acetabular cup system at the time of the index arthroplasty to maximize stability without compromising bony ingrowth into the tantalum components with the use of a constrained liner. Occasionally, we also implement the use of synthetic mesh around the prosthesis to restore the capsule and enhance hip stability.

\section{Conclusions}

Treatment of pelvic tumors is a technically challenging problem that requires careful preoperative planning and execution. Of paramount importance for surgical success is obtaining an adequate surgical margin. With advanced imaging and tumor resection templating, preservation of the limb and reconstruction to restore function is often possible. It is well-accepted that limb preservation (internal hemipelvectomy) is superior to amputation from both a functional and cosmetic perspective. Reconstruction of the pelvis after periacetabular tumor resection using highlyporous metals has become our treatment of choice for many patients, though appropriate resection and reconstruction must be individualized for each patient.

\section{Compliance with Ethics Guidelines}

Conflict of Interest David G. Lewallen has served on boards for the Hip Society and the Orthopedic Research and Education Foundation; has served as a consultant for Zimmer, Pipeline Biomedical, and Ketai Medical Devices; has filed a patent in conjunction with Zimmer; has received royalties from Zimmer; has held stock/stock options in Pipeline Biomedical and Ketai Medical Devices; and has had travel/accommodations expenses covered/reimbursed by the American Joint Replacement Registry and Zimmer. Kevin I. Perry, Matthew P. Abdel, Peter S. Rose, and Franklin H. Sim declare that they have no conflicts of interest.

Human and Animal Rights and Informed Consent This article does not contain any studies with human or animal subjects performed by any of the authors.

\section{References}

References of interest which have been published recently are noted as:

- Of importance

- Of major importance

1. Guo W, Li D, Tang X, Ji T. Surgical treatment of pelvic chondrosarcoma involving periacetabulum. J Surg Oncol. 2010;101(2): 160-5. 
2. Pring ME, Weber KL, Unni KK, Sim FH. Chondrosarcoma of the pelvis. A review of sixty-four cases. J Bone Joint Surg Am. 2001;83-A(11):1630-42.

3. Enneking WF, Dunham WK. Resection and reconstruction for primary neoplasms involving the innominate bone. J Bone Joint Surg Am. 1978;60(6):731-46.

4. O'Connor MI. Malignant pelvic tumors: limb-sparing resection and reconstruction. Semin Surg Oncol. 1997;13(1):49-54.

5. - O'Connor MI, Sim FH. Salvage of the limb in the treatment of malignant pelvic tumors. J Bone Joint Surg Am. 1989;71(4): 481-94.

6. Beadel GP, McLaughlin CE, Aljassir F, Turcotte RE, Isler MH, Ferguson P, et al. Iliosacral resection for primary bone tumors: is pelvic reconstruction necessary? Clin Orthop Relat Res. 2005;438:22-9.

7. Schwartz AJ, Kiatisevi P, Eilber FC, Eilber FR, Eckardt JJ. The Friedman-Eilber resection arthroplasty of the pelvis. Clin Orthop Relat Res. 2009;467(11):2825-30.

8. Fuchs B, O'Connor MI, Kaufman KR, Padgett DJ, Sim FH. Iliofemoral arthrodesis and pseudarthrosis: a long-term functional outcome evaluation. Clin Orthop Relat Res. 2002;397:29-35.

9. Lapras A. Iliofemoral arthrodesis with ischiofemoral bracing. Ann Chir. 1965;19(21):1411-5.

10. Aboulafia AJ, Buch R, Mathews J, Li W, Malawer MM. Reconstruction using the saddle prosthesis following excision of primary and metastatic periacetabular tumors. Clin Orthop Relat Res. 1995;314:203-13.

11. Nieder E, Elson RA, Engelbrecht E, Kasselt MR, Keller A, Steinbrink K. The saddle prosthesis for salvage of the destroyed acetabulum. J Bone Joint Surg Br. 1990;72(6):1014-22.

12. Aljassir F, Beadel GP, Turcotte RE, Griffin AM, Bell RS, Wunder JS, et al. Outcome after pelvic sarcoma resection reconstructed with saddle prosthesis. Clin Orthop Relat Res. 2005;438:36-41.

13. Cottias P, Jeanrot C, Vinh TS, Tomeno B, Anract P. Complications and functional evaluation of 17 saddle prostheses for resection of periacetabular tumors. J Surg Oncol. 2001;78(2):90-100.

14. Mankin HJ, Doppelt SH, Sullivan TR, Tomford WW. Osteoarticular and intercalary allograft transplantation in the management of malignant tumors of bone. Cancer. 1982;50(4):613-30.
15. Harrington KD. The use of hemipelvic allografts or autoclaved grafts for reconstruction after wide resections of malignant tumors of the pelvis. J Bone Joint Surg Am. 1992;74(3):331-41.

16. Dominkus M, Darwish E, Funovics P. Reconstruction of the pelvis after resection of malignant bone tumours in children and adolescents. Recent Results Cancer Res. 2009;179:85-111.

17. Wong KC, Kumta SM, Chiu KH, Antonio GE, Unwin P, Leung KS. Precision tumour resection and reconstruction using imageguided computer navigation. J Bone Joint Surg Br. 2007;89(7): 943-7.

18. •• Khan FA, Rose PS, Yanagisawa M, Lewallen DG, Sim FH. Surgical technique: porous tantalum reconstruction for destructive nonprimary periacetabular tumors. Clin Orthop Relat Res. 2012;470(2):594-601.

19. Levine B, Della Valle CJ, Jacobs JJ. Applications of porous tantalum in total hip arthroplasty. J Am Acad Orthop Surg. 2006;14(12):646-55.

20. Rose PS, Halasy M, Trousdale RT, Hanssen AD, Sim FH, Berry DJ, et al. Preliminary results of tantalum acetabular components for THA after pelvic radiation. Clin Orthop Relat Res. 2006;453:195-8.

21. Siegmeth A, Duncan CP, Masri BA, Kim WY, Garbuz DS. Modular tantalum augments for acetabular defects in revision hip arthroplasty. Clin Orthop Relat Res. 2009;467(1):199-205.

22. Boscainos PJ, Kellett CF, Maury AC, Backstein D, Gross AE. Management of periacetabular bone loss in revision hip arthroplasty. Clin Orthop Relat Res. 2007;465:159-65.

23. Nehme A, Lewallen DG, Hanssen AD. Modular porous metal augments for treatment of severe acetabular bone loss during revision hip arthroplasty. Clin Orthop Relat Res. 2004;429: 201-8.

24. Hugate RR, Dickey ID, Chen Q, Wood CM, Sim FH, Rock MG. Fixed-angle screws vs standard screws in acetabular prosthesis fixation: a cadaveric biomechanical study. J Arthroplasty. 2009;24(5):806-14.

25. Guyen O, Pibarot V, Vaz G, Chevillotte C, Bejui-Hugues J. Use of a dual mobility socket to manage total hip arthroplasty instability. Clin Orthop Relat Res. 2009;467(2):465-72. 